\title{
Concept learning by pigeons: Matching-to-sample with trial-unique video picture stimuli
}

\author{
ANTHONY A. WRIGHT, ROBERT G. COOK, and JACQUELYNE J. RIVERA \\ Graduate School of Biomedical Sciences, University of Texas Health Science Center, Houston, Texas \\ STEPHEN F. SANDS \\ University of Texas, El Paso, Texas \\ and \\ JUAN D. DELIUS \\ Ruhr-Universität, Bochum, West Germany
}

\begin{abstract}
Pigeons were trained to match-to-sample with several new methodologies: a large number of stimuli, computer-drawn color picture stimuli, responses monitored by a computer touch screen, stimuli presented horizontally from the floor, and grain reinforcement delivered onto the picture stimuli. Following acquisition, matching-to-sample concept learning was assessed by transfer to novel stimuli on the first exposure to pairs of novel stimuli. One group (trial-unique), trained with 152 different pictures presented once daily, showed excellent transfer ( $80 \%$ correct). Transfer and baseline performances were equivalent, indicating that the matching-to-sample concept had been learned. A second group (2-stimulus), trained with only two different pictures, showed no evidence of transfer. These results are discussed in terms of the effect of numbers of exemplars on previous failures to find concept learning in pigeons, and the implications of the positive finding from this experiment on abstract concept learning and evolutionary cognitive development.
\end{abstract}

Human cognitive behavior is characterized, in part, by our ability to abstract rules and form abstract concepts (Medin \& Schaffer, 1978). Indeed, even our ability to effectively communicate with others depends upon this ability (Premack, 1978). One question that logically follows from discussions of human cognitive capabilities is: To what degree can animals form and learn concepts? Whether they can or not, bears upon one measure of how unique humans really are in the evolutionary hierarchy of cognitive abilities.

The concepts, which are the focus of this article, are relational ones; they depend upon relations between pairs of items, for example, in situations in which subjects judge whether or not two items are identical (same) or nonidentical (different)-a same/different task-or ones in which they choose a comparison item to match a previously presented sample item-matching-to-sample. It is possible to learn a rule-based concept in these situations, so that any pair of items can be correctly judged. These relational concepts are to be contrasted to those that have been referred to as natural concepts (Medin \& Schaffer, 1978; Herrnstein, Loveland, \& Cable, 1976), class concepts

This research was supported by NIMH Grants MH35202 and MH42881 to the first author. Robert Cook is now at Tufts University. Juan Delius is now at Konstanz University in Konstanz, Federal Republic of Germany, and collaboration on this project was supported by a Deutsche Forschungsgemeinschaft travel grant. Reprint requests should be sent to Anthony A. Wright, Sensory Sciences Center-Suite 316, 6420 Lamar Fleming Avenue, Texas Medical Center, Houston, Texas 77030 .
(Bourne, 1970), and property sets (Hayes-Roth \& HayesRoth, 1977), where the concept is bound by some absolute stimulus property, such as person, water, or tree (Herrnstein et al., 1976). The relational concept, the topic of this article, can be said to be abstract or "higher level" because the stimulus range over which it can be applied is virtually limitless (Premack, 1978). It is the inability of some animals, in particular the pigeon, to form such abstract concepts that has given credence to this capacity as an index of evolutionary cognitive development-an abstract-concept theory of cognitive evolution.

Pigeons have been repeatedly tested for their ability to learn the concept of matching-to-sample, in which a sample or instructional stimulus is presented followed by two (or more) comparison stimuli. The pigeon is trained to choose the comparison that matches the sample. Tests of the pigeon's ability to learn a matching-to-sample concept, by transfer to novel stimuli, have generally yielded negative results (Berryman, Cumming, Cohen, \& Johnson, 1965; Cumming \& Berryman, 1961; Cumming, Berryman, \& Cohen, 1965; Farthing \& Opuda, 1974; Holmes, 1979; Santi, 1978, 1982). Pigeons seem to learn "if ... then" rules related to individual training stimuli and absolute stimulus properties (Carter \& Werner, 1978; Premack, 1978), thus raising the question of whether or not they have the capacity to learn a matching-to-sample concept (Premack, 1978, 1983). But what really do these failures reveal about the pigeon's concept-learning capacity? If such tests show no evidence that the pigeons have learned the concept, is it really a capacity problem or have 
researchers just failed to discover the appropriate training and testing conditions? Functional requirements may restrict the context(s) in which such concepts can be revealed (Sherry \& Schacter, 1987). It seems reasonable that all concept learning, even that by humans, will have some context limitations.

Although most tests have not found pigeons to be capable of learning a matching-to-sample concept, it is clear from some experimental results that they are capable of learning more than just "if ... then" item-specific associations. For example, (1) latencies during transfer testing were longer to the incorrect comparison stimuli than to the correct ones (Urcuioli, 1977; Urcuioli \& Nevin, 1975); (2) relearning showed a savings when compared with relearning after the rule (matching vs. oddity) had been reversed (Zentall \& Edwards, 1984; Zentall, Edwards, \& Hogan, 1984; Zentall, Edwards, Moore, \& Hogan, 1981; Zentall \& Hogan, 1975, 1978, 1981); (3) relearning (with new stimuli) was faster than original learning under procedures that had the pigeons "advance" through serially presented comparison stimuli (Pisacreta, Redwood, \& Witt, 1984); and (4) testing with novel shapes in extinction produced better than chance performance for an average of the first test session, and reacquisition was rapid on subsequent sessions (Lombardi, Fachinelli, \& Delius, 1984).

A question raised by these experiments is, what exactly are the results necessary to substantiate that a concept has been learned? There is no agreement on this issue. Indeed, the claim of many of the experiments cited in the previous paragraph is that they showed concept learning by pigeons. The findings by Zentall and his students cited in the previous paragraph are particularly difficult to explain without resorting to some "higher order" relational rule, because experience is equated for both groups. A difficulty in substantiating that these subjects learned a concept is that the experimental groups frequently showed little or no transfer (even though they always had a performance advantage over the control groups), and in all cases transfer was evaluated from a session average. In the strict sense of the term, a concept that is learned and employed should be transferable, with correct performance exhibited on the very first exposure to new stimuli. If relearning is required, has the concept really been learned? Probably not. At least not to its full extent. Accordingly, the important datum is performance on the first trial with the new stimuli, because relearning can be disguised even in the first session with the new stimuli. If this position should seem extreme, consider that concept learning is itself an extreme form of learning.

The concept learning criteria according to this position have been previously expressed, if in slightly different forms (Premack, 1978; Santiago \& Wright, 1984; Wright, Santiago, Urcuioli, \& Sands, 1984; Wright, Santiago, \& Sands, 1984): (1) Transfer stimuli should be novel, and they should be as different as possible from the training stimuli. It is preferable to avoid combining training and test stimuli on the same trial, because of previous associations with the training stimuli. (2) Transfer results should be limited to the first presentation of the novel stimuli (by virtue of the definition of novelty). Substantial learning can occur even in a single session and disguise the critical results of the first presentation. It is advisable to reinforce correct choices on these test trials with novel stimuli. If the novel stimuli are tested (and retested) in extinction, subjects can associate novel stimuli with nonreinforcement which usually results in artificially lower test performance. (3) In its strongest form, performance on the transfer trials should be as good as baseline performance, and the performance level itself should be well above chance performance.

Previous concept learning experiments have perhaps been most limited by the small number of stimuli employed. There has been little effort to tailor the apparatus specifically to the requirements of concept learning. The stimuli are typically those from the 12-stimuli projector units used in learning experiments, which may not be very well suited for concept learning experiments because they provide: (1) too few training exemplars, (2) too few test stimuli for them to provide, when presented only once, any reliable statistical measure of transfer, (3) too much proactive interference due to repetitions of the small number of training stimuli. Adequate tests of concept learning may require hundreds of distinctly different stimuli. Such a large number of stimuli can be provided by using pictures of everyday scenes and objects-travel slides. Overman and Doty (1980) used 100 such stimuli to train their monkeys in matching-to-sample. The stimuli were presented "trial unique" (presentations limited to one trial daily), and the resulting transfer ( $90 \%$ correct) was equivalent to training performance.

In the experiments reported in this article, one group of pigeons was trained with 152 trial-unique picture stimuli, and a comparison group was trained with only 2 stimuli. Stimulus pairings and sequences varied randomly from day to day. Both groups were tested with novel stimuli; concept development was assessed on the pigeons' first exposure to these novel stimuli. Several new methodological features were introduced in these experiments. These features include: computer-drawn and presented color pictures of objects, responses monitored by a computer touch screen, stimuli presented horizontally from the floor, and grain reinforcement delivered on the picture stimulus. These features were introduced with the intention of making the matching task easier for the pigeons to perform, and it is beyond the scope of these experiments to evaluate their individual contribution.

\section{METHOD}

\section{Subjects}

The subjects were 4 experimentally naive White Carneaux pigeons from the Palmetto Pigeon Plant in Sumter, South Carolina. They were 6 years old at the beginning of the experiments. They were 
maintained on a 14:10-h lights-on:lights-off cycle, with water and grit continuously available. Daily experimental sessions were conducted 5 days each week provided that the pigeons were $77 \%-83 \%$ of their free-feeding weights.

\section{Apparatus}

A drawing of the apparatus is shown in Figure 1. There were several novel aspects to this apparatus that differ from the standard chamber or Skinner box. They included horizontal, rather than vertical, display of the stimuli; pictures displayed on a video monitor; placement of the reinforcer (grain) directly on top of the correct picture; and display of the picture while the grain was eaten from it.

The interior of the experimental chamber where the pigeon resided was $30.5 \mathrm{~cm}$ wide, $34.9 \mathrm{~cm}$ deep, and $35.6 \mathrm{~cm}$ high. (The orientation for all width and depth dimensions are given with respect to the pigeon as it would normally be oriented toward the stimulus display.) Not shown in the drawing was an exhaust fan (McLean INB300S14 with Leviton 6356 rheostat control) mounted on the rear wall $(5.1 \mathrm{~cm}$ below the ceiling and on the center line of the apparatus), and a chamber light (CM1820 with plastic diffuser lens, $24 \mathrm{~V}$ with $300-\Omega$ series resistor) mounted on the ceiling $(17.2 \mathrm{~cm}$ from the rear wall and also on the center line).

The picture stimuli were displayed from a nearly horizontal stimulus panel, tilted slightly $\left(4.4^{\circ}\right)$ toward the pigeon. The pigeon was discouraged from standing on the stimulus display by the presence of an aluminum baffle (also not shown in the drawing), which effectively lowered the ceiling over the stimulus display. This baffle was $21.6 \mathrm{~cm}$ lower than the actual ceiling. It did not obstruct the pigeon's view of the stimuli or its pecking responses to the stimuli, but virtually eliminated standing on the stimulus display.

The picture stimuli were displayed on an Amdek Color IV $(640 \times 350)$ EGA monitor. A special wooden box holding the monitor allowed the monitor to be positioned beneath the opening in the aluminum chamber floor $(23.3 \mathrm{~cm}$ wide $\times 16.7 \mathrm{~cm}$ deep $)$ and to be raised to make contact with it. A total of three pictures could appear at the same time: the sample and the two comparisons. The comparison stimuli were positioned to either side of the sample and slightly closer to the subject. The pictures were framed by cutouts $(6.2 \mathrm{~cm}$ wide $\times 5 \mathrm{~cm}$ deep) in a 6.35 -mm-thick piece of Plexiglas. The top surface of the Plexiglas was covered with walnut-grained contact paper. The cutouts for the comparison stimuli were $.826 \mathrm{~cm}$ from the edge of the monitor hole in the chamber floor that was closest to the subject. The comparison cutouts were $6.35 \mathrm{~mm}$ to either side of the sample stimulus cutout, and the bottom edge of

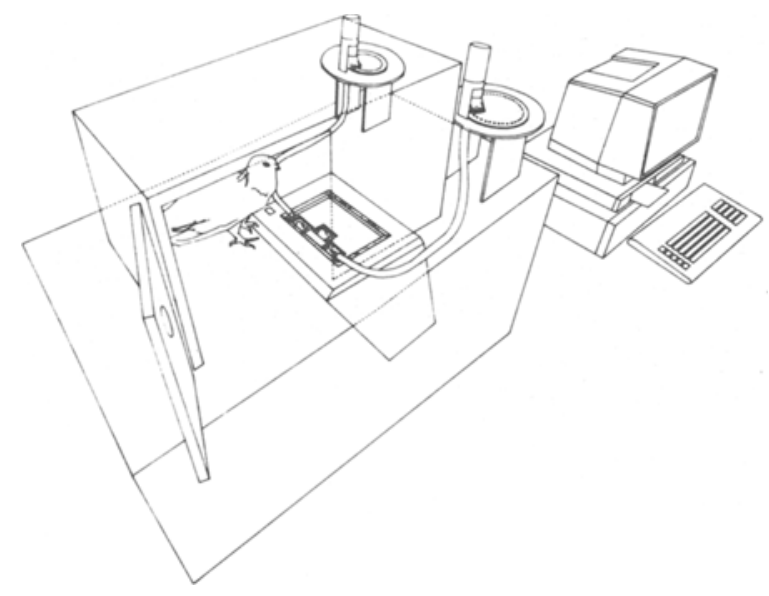

Figure 1. Artist's drawing of the apparatus showing the horizontal stimulus display, video monitor (cutaway), grain feeders, and tubes positioned to dispense grain onto the side stimuli. the sample cutout overlapped the top edge of the comparison ones by $.127 \mathrm{~cm}$.

The pigeons' pecking responses were sensed by a touch screen (Soft-touch Model 6020, Aquila Technologies, Albuquerque, NM) composed of a matrix (27 wide $\times 21$ deep) of infrared, lightemitting diodes (LEDs) and photosensors. A pigeon's beak could not be inserted into the LED matrix without triggering a response, but only the responses within the cutout areas were active for the purposes of these experiments.

\section{Reinforcement Delivery}

Grain reinforcers were delivered onto the screen within the cutout containing the correct comparison stimulus. The mechanism for grain delivery was constructed by joining a shaving brush (as a grain reservoir) to a modified rat pellet dispenser (Scientific Prototype Model D700). The holes around the perimeter of the pellet-dispenser plate were enlarged to $17.9 \mathrm{~mm}$ (5/16 drill), and the plate was raised to $6.35 \mathrm{~mm}$. A 6.35-mm-thick sector plate was placed beneath the region of the drop hole and the cylinder-brush mechanism holding the grain. Thus, there was an air gap of $6.35 \mathrm{~mm}$ below most of the area of the plate, which virtually eliminated jamming by the accumulation of chaff and dust. The center hole of the shaving brush (Gillette Brush Plus) was enlarged to $12.7 \mathrm{~mm}$ diameter, and the shaving brush was supported (by bracket and hose clamps) in such a way that the pressure it exerted on the dispenser plate was sufficient to wipe off excess grain. Grain dropped a vertical distance of approximately $22.9 \mathrm{~cm}$ down polyethylene tubing (Lancer 7920 , $1.27 \mathrm{~cm} \mathrm{i.d.).} \mathrm{The} \mathrm{terminal} \mathrm{ends} \mathrm{of} \mathrm{the} \mathrm{tubing} \mathrm{were} \mathrm{held} \mathrm{by} \mathrm{wooden}$ blocks (not shown in the drawing), drilled to snugly fit the tubing and adjustable in orientation so that they pointed toward the center of the comparison stimulus cutouts. Length of the tubing controlled the rate of descent of grain, and was adjusted so the grain would drop onto the center of the comparison stimulus cutouts.

\section{Stimuli}

The 232 picture stimuli were full color cartoons drawn by hand with a computer graphics editor program written by one of the authors (S.F.S.). The pictures were, in many cases, adaptations of a standardized set of line drawings (Snodgrass \& Vanderwart, 1980). Figure 2 shows black-and-white photographs of several of the training and transfer stimuli.

The training stimulus set: accordion, airplane, alligator, anchor, ant, apple, arrow, bolt, ax, baby carriage, beach ball, football, balloon, banana, barn, barrel, bear, bed, bee, beetle, bicycle, jacket, closed dictionary, bow, box, sliced bread, brush, bus, button, cake, candle, cannon, car, carrot, baseball cap, cat, celery, chair, cherry, chicken, church, cigar, cigarette, clown, corn on cob, crown, cup, desk, dog, donkey, door, doorknob, dress, drum, duck, eagle, bull elephant, envelope, ewe, eye, fence, file, fish, flag, flower, fly, fox, french horn, frog, trash can, eyeglasses, blue gloves, gorilla, big purple grapes, grasshopper, hammer, hand, hanger, harp, derby hat, heart, helmet, horse, house, iron, jacket, kettle, key, knife, ladder, lamp, leaf, lettuce, light bulb, lion, lips, lobster, lock, mitten, quarter moon, motorcycle, mushroom, nail, necklace, washer, onion, orange, ostrich, owl, paintbrush, pants, peacock, peanut, pear, pen, pencil, penguin, pepper, piano, pineapple, pitcher, pliers, electrical plug, pot, potato, pumpkin, rabbit, raccoon, record player, ram, refrigerator, rhinoceros, finger ring, rocking chair, rooster, salt, sandwich, scissors, screwdriver, sea horse, shirt, skillet, skirt, sled, snail, snake, snowman, sock, spider, light switch, spool of thread, volcano.

The transfer stimulus set: arm and fist, artichoke, asparagus, basket, belt, open picture book, boot, boy, broom, camel, watering can, chalice, clock, coat, couch, cow, deer, dresser, ear, small baby elephant, potted flowers, foot, fork, giraffe, glass, goat, small green grapes, guitar, gun, ironing board, kangaroo, kite, leopard, 

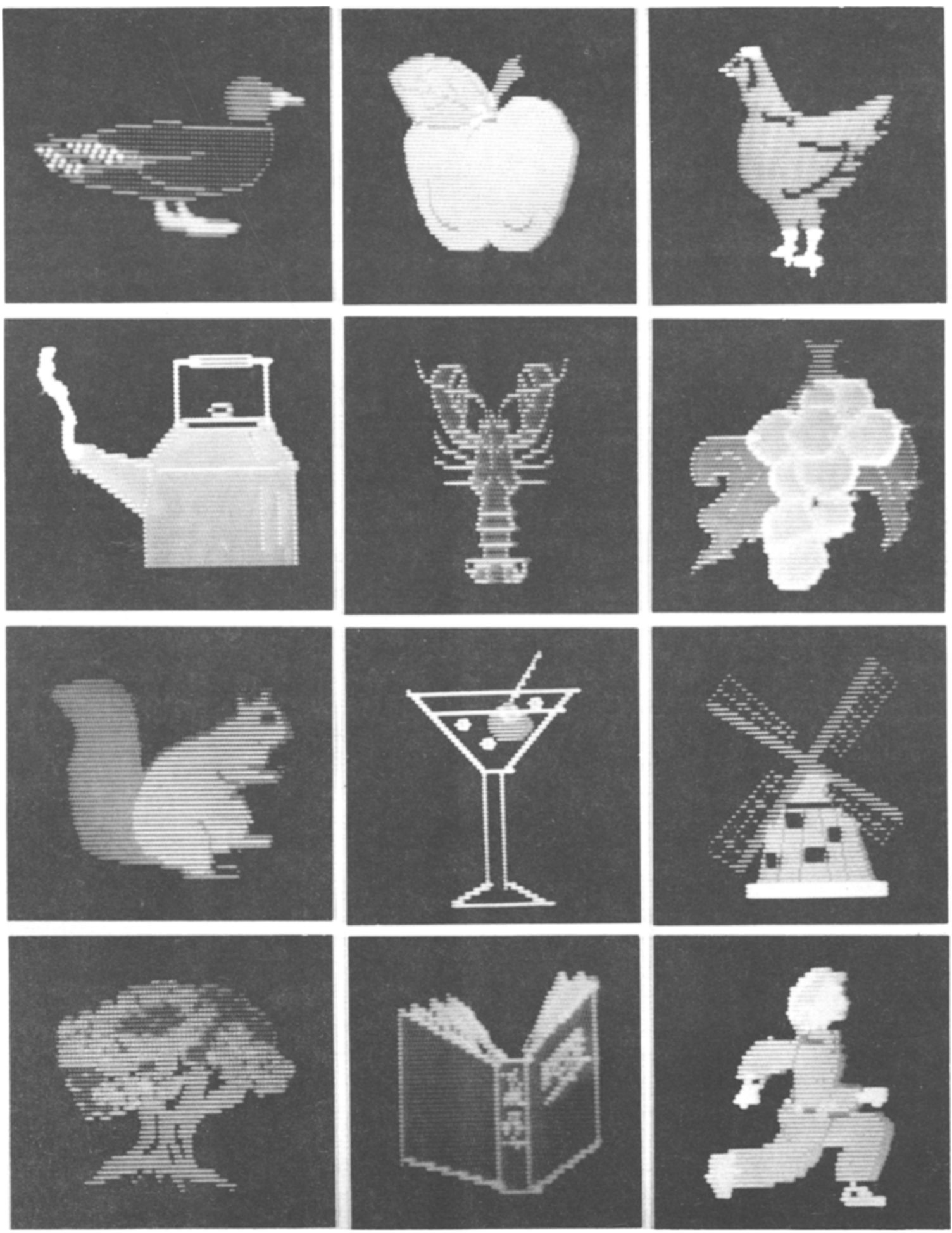

Figure 2. Black and white photographs of 12 of the 232 color video picture stimuli used in the experiments. The first 2 are the training stimuli used for the 2-stimulus group. The first 6 were 6 of the 152 training stimuli of the trial-unique group. The last 6 were 6 of the 80 transfer stimuli used in these experiments. The pictures were presented in full color on the computer screen: brown duck with green head and yellow bill and feet; red apple with green leaf and brown stem; red chicken with yellow beak and feet; blue kettle with brown and white handle, red lid knob, and white steam; red lobster with pink outline; purple grapes with green leaves and brown stem; brown squirrel with reddish tail; white martini with green and red (pimiento) olive; pink windmill with brown blades and a white foundation; brown oak tree with light and dark green leaves; dark blue book with white outline; flesh-colored boy with blonde hair, blue pants, red shirt, and light-blue shoes. 
traffic light, martini, mouse, persimmon, pig, pipe, purse, rolling pin, saw, shoe, skunk, squirrel, stool, stove, strawberry, suitcase, sun, swan, sweater, swing, table, telephone, television, spool of string, tie, toaster, tomato, toothbrush, spinning top, oak tree, willow tree, truck, turtle, umbrella, vase, vest, violin, wagon, watch, watermelon, water well, ferris wheel, spoke wheel, whistle, windmill, window, wrench.

\section{Procedure}

\section{Response Shaping}

Response shaping was accomplished rapidly by the placement of grain directly on top of the stimulus. Both right and left comparison stimuli were used in autoshaping. After the stimulus picture was displayed for $6 \mathrm{sec}$, grain was placed on top of it. The picture continued to be displayed for an additional $12 \mathrm{sec}$ while the grain was eaten. Two pictures (apple and arrow) were used during shaping (apple and duck were the stimuli used with the 2-stimulus group). Each stimulus was used on six consecutive autoshaping trials, with left and right positions alternating, and with the left/right starting position determined randomly. The houselight was turned on only during the intertrial interval, which varied randomly, from 25 to $60 \mathrm{sec}$. This shaping procedure was repeated on 2 consecutive days, after which the matching-to-sample experiment began.

\section{Training}

General. During the first 35 trials of the first session, grain was placed on the correct comparison stimulus before the pigeon made its choice response. When the pigeon pecked the grain, thus making the correct response, it received more grain (reward for the correct response). This autolearning procedure helped to get the pigeons started in the task.

Subsequent trials and sessions proceeded according to a simultaneous matching-to-sample format. The sample stimulus was presented for a fixed interval of $2 \mathrm{sec}$, after which a peck produced the comparison stimuli on each side. The comparison stimuli (and sample stimulus) remained in view until a response was made to one of them. A response to the correct comparison turned off the incorrect comparison stimulus and produced grain reinforcement on top of the correct comparison stimulus. The sample remained in view for $1 \mathrm{sec}$ following offset of the incorrect comparison. The correct comparison stimulus remained on for $10 \mathrm{sec}$ to allow enough time for the grain to be consumed in its presence. An intertrial interval of $15 \mathrm{sec}$ followed offset of the correct comparison stimulus. A response to the incorrect comparison stimulus turned the incorrect comparison stimulus off immediately, the sample stimulus $1 \mathrm{sec}$ later, and the correct comparison stimulus $2 \mathrm{sec}$ after that. This was followed by the 15 -sec intertrial interval. Trials on which an incorrect response was made were repeated until the correct response was made. Correct responses were followed by grain reinforcement-safflower seeds (mean $=3.3, S D=1.2$ ) for correct right responses, and wheat seeds (mean $=4.4, S D=1.5$ ) for correct left responses. The different grain types were of no intrinsic importance to this experiment, but it was anticipated that they might be in a same/different task, and so were used in this experiment in order to preserve the possibility of making direct comparisons between the two experiments.

Trial-unique group. The 2 pigeons in the trial-unique group were presented with 152 different stimuli daily, and each stimulus appeared in only 1 of the 76 trials (hence, trial unique). The pairings of the stimuli to make up trials and the side on which the correct comparison appeared varied randomly daily.

2-stimulus group. The 2 pigeons in the 2-stimulus group were presented with only two different stimuli daily (duck and apple), and each stimulus appeared on each of the 76 trials (half the time as the sample and correct comparison and half the time as the incorrect comparison). When they performed at $75 \%$ correct or better, they were tested for transfer.

\section{Transfer}

General. Ten transfer trials were conducted during a transfer session. Since 2 novel stimuli were used in each transfer trial, a total of 20 novel stimuli were used in each transfer test session. The first 25 trials of each transfer session were warm-up trials. The 10 transfer trials were then intermixed within the remaining 51 trials, separated by a minimum of 3 training trials. The particular position of the transfer trials varied from test to test. To control for the number of exposures to the novel stimuli, the correction procedure was not used during transfer testing. Two consecutive transfer sessions were conducted with a different 20 transfer stimuli tested each day, for a total of $\mathbf{4 0}$ stimuli. The first $\mathbf{4 0}$ novel stimuli are referred to as Set $\mathbf{A}$.

Trial-unique group. The slow acquisition by this group allowed for transfer testing during acquisition. The first transfer test and a retest of these same stimuli were conducted before these subjects achieved the $75 \%$ performance criterion. During the first retest, the stimuli were tested twice (instead of just once, as during the transfer test) and pairings of the stimuli and positions of the test trials in the sessions were different from those of the first transfer session. The rationale for these retests was that the pigeons were unlikely to perform well with any additional test stimuli if they did not perform well with those that had been used in the first transfer test. Since the number of test stimuli was somewhat limited, those of Set B were reserved for the possibility that the pigeons would eventually perform well with those of Set $A$.

The second and final transfer test was a transfer test of 40 new and completely novel test stimuli (Set B), which followed yet another retest (fourth test) of the previous $\mathbf{4 0}$ test stimuli (Set A). These novel stimuli were tested in a manner similar to that used for Set A.

2-stimulus group. Except for the stimuli on the training trials, the transfer test of this group was identical to the first transfer test of the trial-unique group.

\section{RESULTS}

\section{Acquisition}

Acquisition of matching-to-sample by the trial-unique group is shown in Figure 3. Mean performance on consecutive blocks of four sessions is shown in this figure. Although acquisition was slow, it rose from chance performance to about $75 \%$ correct over 360 training sessions covering 18 months of experimentation.

Acquisition of matching-to-sample by the 2-stimulus group is shown in Figure 4. Performance on individual sessions, rather than blocks of 4 sessions, is shown in this figure. The $75 \%$ performance criterion was achieved on the 16th session by both subjects.

Another way to compare the acquisition of the two groups is in terms of the frequency of exposure to individual items rather than by sessions or session blocks. The 2-stimulus group was presented with each item on all of the 76 trials for a total of 1,216 presentations over the 16 acquisition sessions. The trial-unique group was presented with each item only once each session for a total of 360 presentations over the 360 acquisition sessions. Thus, the trial-unique group required fewer presentations of each individual item to acquire the task than did the 2-stimulus group. Apparently there was transfer of learning between the stimuli which produced faster learning, at least on a per-exposure basis, for the trial-unique group than for the 2-stimulus group. This facilitation of acqui- 


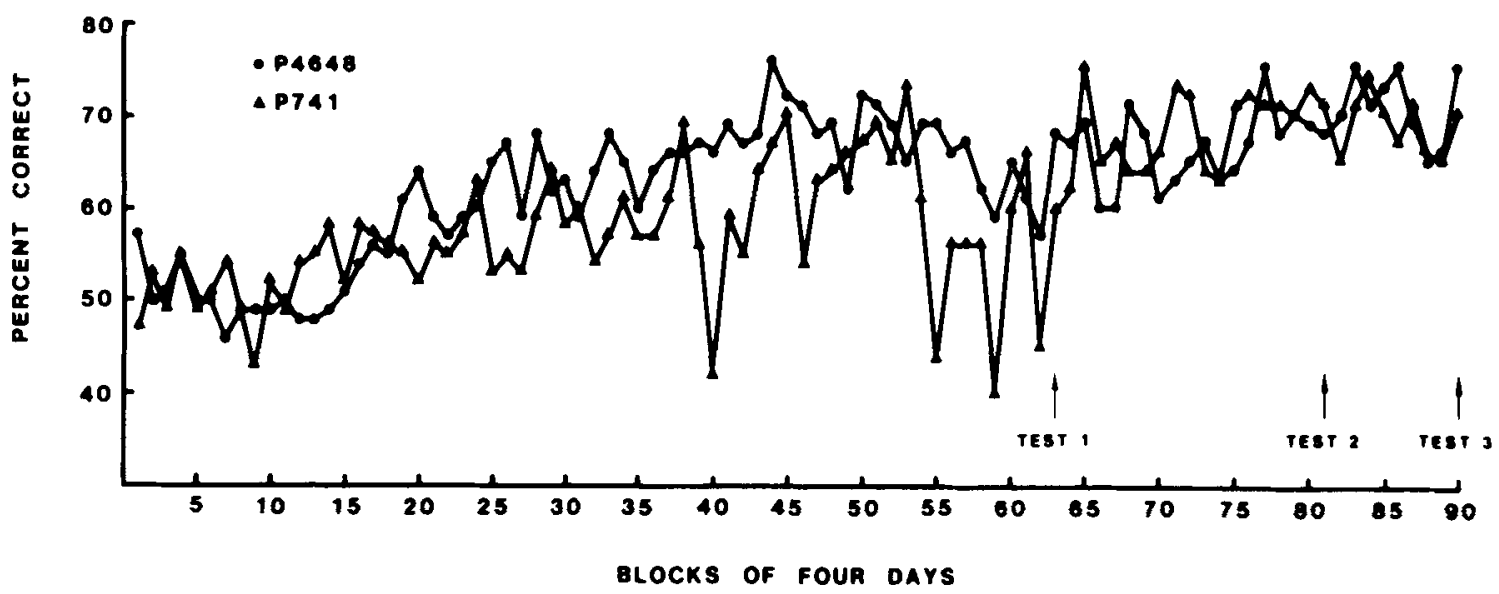

Figure 3. Matching-to-sample acquisition for the 2 pigeons trained with 152 trial-unique stimuli for 76 trinls each daily seasion. Performance is shown as an average (mean) for each consecutive block of four sessions. The arrows and test numbers indicate when transfer tests were conducted.

sition on a per-exposure basis indicates that something in addition to a series of "if ... then" rules were learned by the trial-unique group. This result provides some indirect evidence that a more generalized matching rule was being learned. The transfer tests were a more direct test of whether these pigeons learned a generalized matching rule.

\section{Transfer}

Transfer performance for the trial-unique subjects, P4648 and P741, is shown in Figures 5 and 6, respectively. These figures show that by the final retest of Set $A$ (Test 3), both subjects were performing as well with Set $A$ stimuli as they had with the baseline stimuli $[F(1,6)=$ $5.1, p=.07$, with individual transfer sessions treated in-

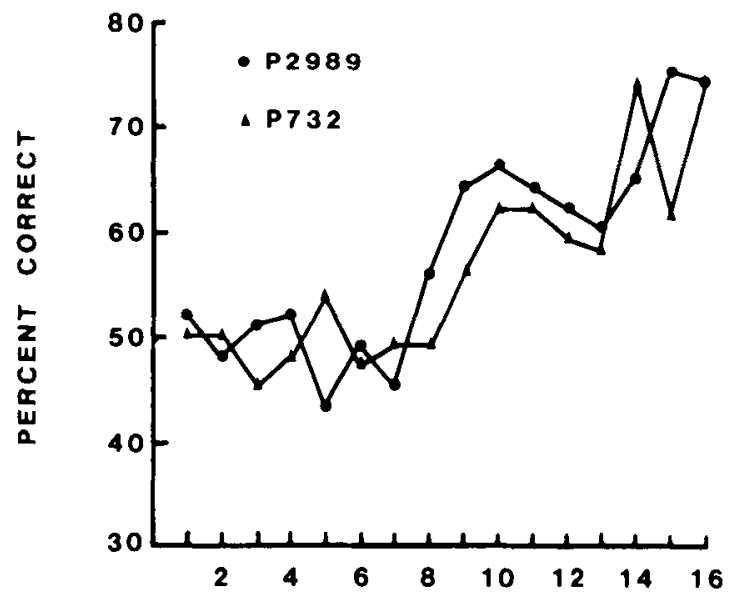

DAYS

Figure 4. Matching-to-sample acquisition for 2 pigeons trained with 2 stimuli for 76 trials each daily session. Performance is shown as a daily session average (mean). The first transfer test was conducted on Day 17 immediately following acquisition. dependently]. Baseline performance was even somewhat better $(83 \%)$ during the last transfer test (Test 3 ) than it had been $(75 \%)$ at the conclusion of acquisition. The transfer trials, with their new stimuli, apparently enhanced performance on the training trials. We have observed such enhancements before with both pigeon and monkey subjects. Establishing that Set A performance was as good as the baseline performance for both subjects provided the necessary conditions for the testing of novel Set B. Performance with the novel stimuli of Set B is shown for the individual subjects in Figures 5 and 6 (rightmost histograms). As with the retested Set $A$, their performance with this novel Set B was at or above $80 \%$ correct. The group average is shown in Figure 7 along with the group average for the 2-stimulus group.

Figure 7 shows that the baseline and test performances for the trial-unique group were equivalent $[F(1,6)=3.8$, $p=.85$, with individual transfer sessions treated independently and with the baseline performance from only the two sessions on which Set B was tested]. Included in Figure 7 is the average transfer performance for the 2stimulus group. These two groups were tested when their performance in the task had reached the same criterion level. The baseline performance during the test for the 2-stimulus group is virtually identical to that of the trialunique group, but unlike the trial-unique group, which shows total transfer, the 2-stimulus group shows transfer that is significantly different from baseline $[F(1,6)=13.8$, $p=.01$, with individual transfer sessions treated independently]. In fact, neither subject's transfer was significantly different from the $50 \%$ chance level $(p=.82$, binomial test).

\section{Additional Training and Tests of the 2-Stimulus Group}

The main purpose of the 2-stimulus group was to provide a transfer comparison for the trial-unique group at the same acquisition stage and performance level. Following this transfer test, other training and testing was 

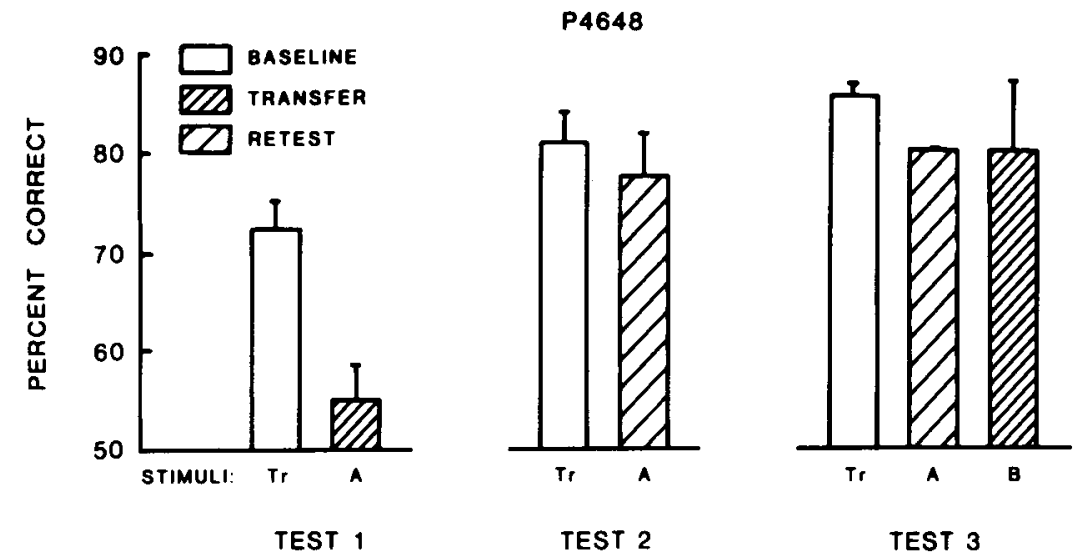

Figure 5. Baseline, transfer, and retraining performance from Pigeon P4648 on three tests. Performance was tested to a set of 152 training (Tr) stimuli and two different test sets (A and B) of $\mathbf{4 0}$ test stimuli each. Error bars are standard errors of the mean.

conducted. It was largely exploratory, and is briefly discussed here because it shows just how strong and rigid the absolute-stimulus or item-specific associations of subjects trained with only two stimuli could be.

One subject, P2989, was trained and tested for an additional 244 sessions. Included was training with two new stimuli (candle and ball) in addition to the two original ones (duck and apple). Of some interest was that it was very difficult to train this subject to perform well with the new stimuli. This subject was trained with trials in which new stimuli were separated from old ones, trials in which the two were mixed, and trials in which the old stimuli gradually faded into the new ones by means of drawing pictures (10 each) which gradually changed the duck into a candle and the apple into a ball. Additionally, various parameters were manipulated for both of the subjects (P732 was trained and tested for an additional 48 sessions) to see if some manipulation might help transfer. These manipulations included turning off all the stimuli at the same time (but at different times following correct and incorrect choices), doubling the amount of reinforcement for correct responses, delivering the same reinforcer (wheat) for right and left correct responses, and gradually shrinking the size of the stimuli. Retest performance of the Set A stimuli averaged 53\% correct, while their baseline performance was maintained at $78 \%$ correct during these tests. Transfer to Set B stimuli was also tested during this time, and it averaged $51 \%$ correct for transfer and retest by both subjects, while their baseline performance averaged $76 \%$ correct.

\section{DISCUSSION}

The research reported in this article clearly shows that pigeons can learn an abstract concept, in this case the concept of matching-to-sample. This finding is in stark contrast to previous claims that pigeons learn only itemspecific, absolute stimulus properties, and "if ... then" associations (Carter \& Werner, 1978; Premack, 1978, 1983). The ability to learn a concept, however, does not mean that this is the pigeon's preferred learning strategy. Quite to the contrary, it is clear from the vast amount of
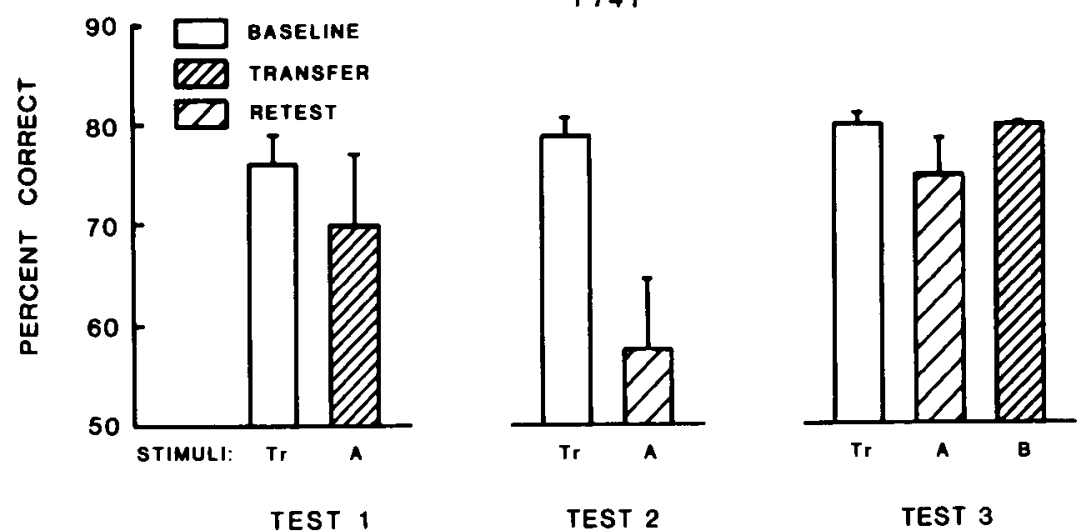

Figure 6. Baseline, transfer, and retraining performance from Pigeon P741 on three tests. Performance was tested to a set of 152 training (Tr) stimuli and two different test sets (A and B) of $\mathbf{4 0}$ test stimuli each. Error bars are standard errors of the mean. 


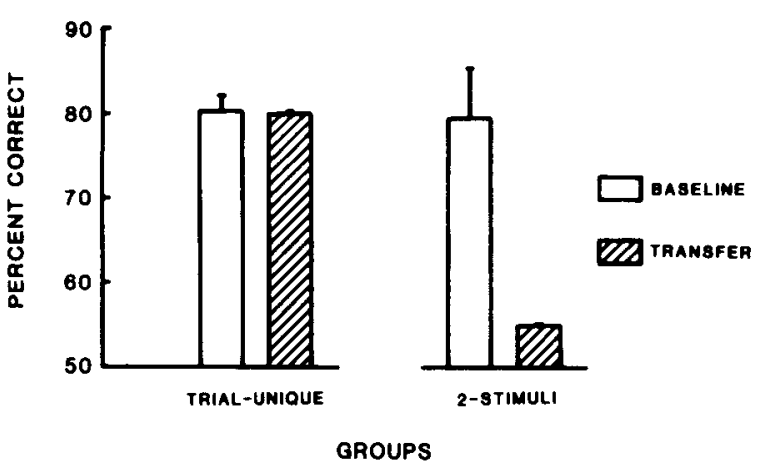

Figure 7. Left: Mean baseline and transfer performance (Set B, Test 3) for both subjects of the trial-unique group. Right: Mean baseline and transfer performance of both subjects of the 2-stimulus group. Error bars are standard errors of the mean for the subjects in each group combined.

research with pigeons that they prefer to attend to absolute stimulus properties and to form item-specific associations. But strategy preference is not the issue in these investigations of abstract concept learning. The issue is: Do pigeons have the capacity to learn and employ an abstract concept? Previous tests of pigeon abstract concept learning ability may have been dominated by the pigeon's preference for forming item-specific associations. Although there are many procedural and apparatus differences between this experiment and previous tests, the crucial one may be the number of training stimuli. The trialunique group was trained with 152 stimuli, and learned the concept. Pigeons trained with only 2 stimuli did not learn it. Furthermore, pigeons trained with 2 stimuli showed little or no learning with 2 added stimuli, even after prolonged training. Previous tests of pigeon concept learning have used small numbers of stimuli, which may have been responsible for those pigeons' not learning the concept. Indications regarding the role of larger numbers of stimuli in monkey concept learning have been in the literature for some time (e.g., Moon \& Harlow, 1955), and other such indications have appeared more recently (e.g., Overman \& Doty, 1980; Wright, Santiago, \& Sands, 1984; Wright, Santiago, Urcuioli, \& Sands, 1984). It is clear also that, even for humans, the degree of concept learning attained (e.g., category learning with subsets of a dot matrix; see Posner \& Keele, 1968) depends upon the number of exemplars involved (Homa \& Chambliss, 1975; Homa, Cross, Cornell, Goldman, \& Shwartz, 1973; Homa, Sterling, \& Treple, 1981; Homa \& Vosburgh, 1976; Omohundro, 1981). Related is the natural category learning by pigeons, and here, too, the degree to which they learn these concepts seems to depend upon the number of training exemplars used (Cook, Wright, \& Kendrick, in press).

Although group sizes in the present experiment were small, this should not be viewed as a limitation on the general finding. This research provided a positive answer to the important question, Do pigeons have the capacity to learn an abstract concept such as matching-to-sample? In the extreme case, a positive finding from only one subject can answer this question. Such a result would show that at least one species of avian, the pigeon, has the capacity to learn an abstract concept. It is unlikely that pigeons, or any avian species, could demonstrate such abilities in all contexts (see Sherry \& Schacter, 1987). Animals may not exhibit their cognitive abilities in precisely the same contexts as do humans with, say, verbal material. But this should not be viewed necessarily as a deficiency. Indeed, if experimenter and subject roles were reversed, pigeons might view us as limited in at least some capacities, because we cannot see ultraviolet light as they can (Wright, 1972) or hear ultrasound as they can (Kreithen, 1979).

The other side of the coin is that it is somewhat inconsequential to discover contexts or individuals who fail to show a particular capacity. These are failures-to-find, null results, and from them one can conclude only to suspend judgment. Possibly through exhaustive tests and converging lines of evidence, one could make a convincing case that abstract concept learning was beyond the capacity of some species, but there might be some lingering doubt that the right context had not been discovered and tested. A single positive result, on the other hand, is an existence proof that such capacity exists.

\section{REFERENCES}

Berryman, R., Cumming, W. W., Cohen, L. R., Johnson, D. F. (1965). Acquisition and transfer of simultaneous oddity. Psychological Reports, 17, 767-775.

Bourne, L. E., Jr. (1970). Knowing and using concepts. Psychological Review, 77, 546-556.

Carter, D. E., \& Werner, T. J. (1978). Complex learning and information processing by pigeons: A critical analysis. Joumal of the $E x-$ perimental Analysis of Behavior, 29, 565-601.

Cook, R. G., Wright, A. A., \&e Kendrick, D. F. (in press). Principles of categorization in pigeons and humans. In $\mathrm{M}$. L. Commons \& R. J. Hermstein (Eds.), Quantitative analyses of behavior (Vol. 8). Cambridge, MA: Ballinger.

Cumming, W. W., Berryman, R. (1961). Some data on matching behavior in the pigeon. Journal of the Experimental Analysis of Behavior, 4, 281-284.

Cumming, W. W., Berryman, R., Cohen, L. R. (1965). Acquisition and transfer of zero delay matching. Psychological Reports, 17, 435-445.

FARThING, G. W., \& OPUDA, M. J. (1974). Transfer of matching-tosample in pigeons. Journal of the Experimental Analysis of Behavior, 21, 199-213.

Hayes-Roth, B., \& Hayes-Roth, F. (1977). Concept learning and the recognition and classification of exemplars. Journal of Verbal Leaming \& Verbal Behavior, 16, 321-338.

Herrnstein, R. J., Loveland, D. H., Cable, C. (1976). Natural concepts in pigeons. Journal of Experimental Psychology: Animal Behavior Processes, 2, 285-302.

Holmes, P. W. (1979). Transfer of matching performance in pigeons. Journal of the Experimental Analysis of Behavior, 31, 103-114.

HомА, D., \& CHAMBLiss, D. (1975). The relative contributions of common and distinctive information on the abstraction from ill-defined categories. Journal of Experimental Psychology: Human Learning \& Memory, 1, 351-359. 
Homa, D., Cross, J., Cornell, D., Goldman, D., Shwartz, S. (1973). Prototype abstraction and classification of new instances as a function of number of instances defining the prototype. Joumal of Experimental Psychology, 101, 116-122.

Homa, D., Sterling, S., \& Treple, L. (1981). Limitations of exemplarbased generalization and the abstraction of categorical information. Joumal of Experimental Psychology: Human Learming \& Memory, 7, 418-439.

Homa, D., \& Vosburgh, R. (1976). Category breadth and the abstraction of prototypical information. Joumal of Experimental Psychology: Human Learning \& Memory, 2, 322-330.

Kreithen, M. L. (1979). The sensory world of the homing pigeon. In A. M. Granda \& J. H. Maxwell (Eds.), Neural mechanisms of be havior in the pigeon (pp. 21-33). New York: Plenum Press.

Lombard, C. M., Fachinelli, C. C., \& Delius, J, D. (1984). Oddity of visual patterns conceptualized by pigeons. Animal Leaming \& Behavior, 12, 2-6.

Medin, D. L., SChafFer, M. M. (1978). Context theory of classification learning. Psychological Review, 85, 207-238.

Moon, L. E. HarLow, H. F. (1955). Analysis of oddity learning by rhesus monkeys. Journal of Comparative \& Physiological Psychology, 48, 188-195.

OMOHUNDro, J. (1981). Recognition vs. classification of ill-defined category exemplars. Memory \& Cognition, 9, 324-331.

Overman, W. H., JR., \& DOTY, R. W. (1980). Prolonged visual memory in macaques and man. Neuroscience, 5, 1825-1831.

Pisacreta, R., Redwood, E., \& WITT, K. (1984). Transfer of matching to-figure samples in the pigeon. Journal of the Experimental Analysis of Behavior, 42, 223-237.

PosNer, M. I., KEele, S. W. (1968). On the genesis of abstract ideas. Joumal of Experimental Psychology, 77, 353-363.

Premack, D. (1978). On the abstractness of human concepts: Why it would be difficult to talk to a pigeon. In S. H. Hulse, H. Fowler, \& W. K. Honig (Eds.), Cognitive processes in animal behavior (pp. 423-451). Hillsdale, NJ: Erlbaum.

Premack, D. (1983). Animal cognition. Annual Review of Psychology, 34, 351-362.

SANTI, A. (1978). The role of physical identity of the sample and correct comparison stimulus in matching-to-sample paradigms. Journal of the Experimental Analysis of Behavior, 29, 511-516.

SANTI, A. (1982). Hue matching and hue oddity in pigeons: Is explicit training not to peck incorrect hue combinations a sufficient condition for transfer? Psychological Record, 32, 61-73.

Santiago, H. C., Wright, A. A. (1984). Pigeon memory: Same/different concept learning, serial probe recognition acquisition and probe delay effects in the serial position function. Joumal of $E x-$ perimental Psychology: Animal Behavior Processes, 10, 498-512.
SHERrY, D. F., SChacter, D. L. (1987). The evolution of multiple memory systems. Psychological Review, 94, 439-454.

SNOdGRaSS, J. G., VANDERWART, M. (1980). A standardized set of 260 pictures: Norms for name agreement, image agreement, familiarity, and visual complexity. Journal of Experimental Psychology: $\mathrm{Hu}$ man Learning \& Memory, 6, 174-215.

URCuIOLI, P. J. (1977). Transfer of oddity-from-sample performance in pigeons. Journal of the Experimental Analysis of Behavior, 25, 195-202.

URCuloLi, P. J., \& Nevin, J. A. (1975). Transfer of the hue matching in pigeons. Journal of the Experimental Analysis of Behavior, 24, 149-155.

Wrighr, A. A. (1972). The influence of ultraviolet radiation on the pigeon's color discrimination. Journal of the Experimental Analysis of Behavior, 17, 325-337.

Wright, A. A., Santiago, H. C., \& Sands, S. F. (1984). Monkey memory: Same/different concept learning, serial probe acquisition, and probe delay effects. Jourmal of Experimental Psychology: Animal Behavior Processes, 10, 513-529.

Wright, A. A., Santiago, H. C., Urcuioli, P. J., \& Sands, S. F. (1984). Monkey and pigeon acquisition of same/different concept using pictorial stimuli. In M. L. Commons \& R. J. Hermstein (Eds.), Quantitative analysis of behavior (Vol. 4, pp. 295-317). Cambridge, MA: Ballinger.

ZenTALL, T. R., \& EDwards, C. A. (1984). Categorical color coding by pigeons. Animal Learning \& Behavior, 12, 249-255.

Zentall, T. R., Edwards, C. A., \& Hogan, D. E. (1984). Pigeons' use of identity. In M. L. Commons, R. J. Hermstein, \& A. R. Wagner (Eds.), Quantitative analyses of behavior discrimination processes (Vol. 4, pp. 273-293). Cambridge, MA: Ballinger.

Zentall, T. R., Edwards, C. A., Moore, B. S., \& Hogan, D. E. (1981). Identity: The basis for both matching and oddity learning in pigeons. Journal of Experimental Psychology, 7, 70-86.

Zentall, T. R., \& Hogan, D. E. (1975). Concept learning in the pigeon: Transfer to new matching and nonmatching stimuli. American Journal of Psychology, 88, 233-244.

Zentall, T. R., \& Hogan, D. E. (1978). Same/different concept learning in the pigeon: The effect of negative instances and prior adaptation to transfer stimuli. Journal of the Experimental Analysis of Behavior, 30, 177-186.

Zentall, T. R., Hogan, D. E. (1981). Pigeons can learn identity of difference, or both. Science, 191, 408-409.

(Manuscript received October 21, 1987; revision accepted for publication May 6, 1988.) 